Saudi Journal of Medicine

Abbreviated Key Title: Saudi J Med ISSN 2518-3389 (Print) |ISSN 2518-3397 (Online) Scholars Middle East Publishers, Dubai, United Arab Emirates Journal homepage: https://saudijournals.com/sjm

Case Report

\title{
Malignant Transformation: Dreadful Complication of A Choledochal Cyst
} Hicham Dahmane*, Ayman Chakiri, Faysal Alazaoui, Hadj Omar El Malki, Mountassir Chefchaouni, Lahsen Ifrine, Abdelkader Belkouchi

Chirurgie A, Ibn Sina Hospital, Mohammed V University Rabat, Morocco

DOI: $10.36348 / \mathrm{sjm} .2020 . v 05 i 09.001$

| Received: 27.08.2020 | Accepted: 03.09.2020 | Published: 09.09.2020

*Corresponding Author: Hicham Dahmane

\section{Abstract}

Choledochal cysts are a rare congenital anomaly, the malignant degeneration is the most dreadful complication of this pathology with a very unfavorable prognosis, and we report an observation illustrating this complication and its prognostic in a young woman taken in charge in our unit.

Keywords: Choledochal cyst; malignant transformation.

Copyright @ 2020: This is an open-access article distributed under the terms of the Creative Commons Attribution license which permits unrestricted use, distribution, and reproduction in any medium for non-commercial use (NonCommercial, or CC-BY-NC) provided the original author and source are credited.

\section{INTRODUCTION}

Considered a true pre-cancerous condition, choledochal cyst is a rare congenital anomaly resulting essentially from a bilio pancreatic junction anomaly, and requiring adequate surgical management.

Considered a true pre-cancerous condition, cystic dilatation of the choledochus and a rare congenital anomaly resulting essentially from a biliopancreatic junction anomaly, and requiring adequate surgical management.

\section{OBSERVATION}

We report the case of a 31 year old patient admitted for management of cholestatic jaundice associated with epigastric pain, the abdominal ultrasound had revealed a cystic formation of the main biliary tract, which was completed by MRI (Figure 1) which showed a bile duct dilated to $5 \mathrm{~cm}$ thick and tortuous down to the bottom with visibility of the Wirsung achieving a grade I according to the Todani classification.

The patient Benefited surgical treatment with first resection of the bile duct cyst (Figures 2, 3, 4, 5) and sent for extemporaneous examination, the result was in favour of a malignant transformation and the procedure was completed by a cephalic duodenopancreatectomy. The postoperative follow-up was simple and the anatomopathological examination was in favour of a biliary adenocarcinoma. 5 months after surgery the patient was admitted with diffuse abdominal pain with vomiting and alteration of the general condition the abdominal CT scan was in favour of generalized peritoneal carcinosis, patient died 6 months postoperatively.
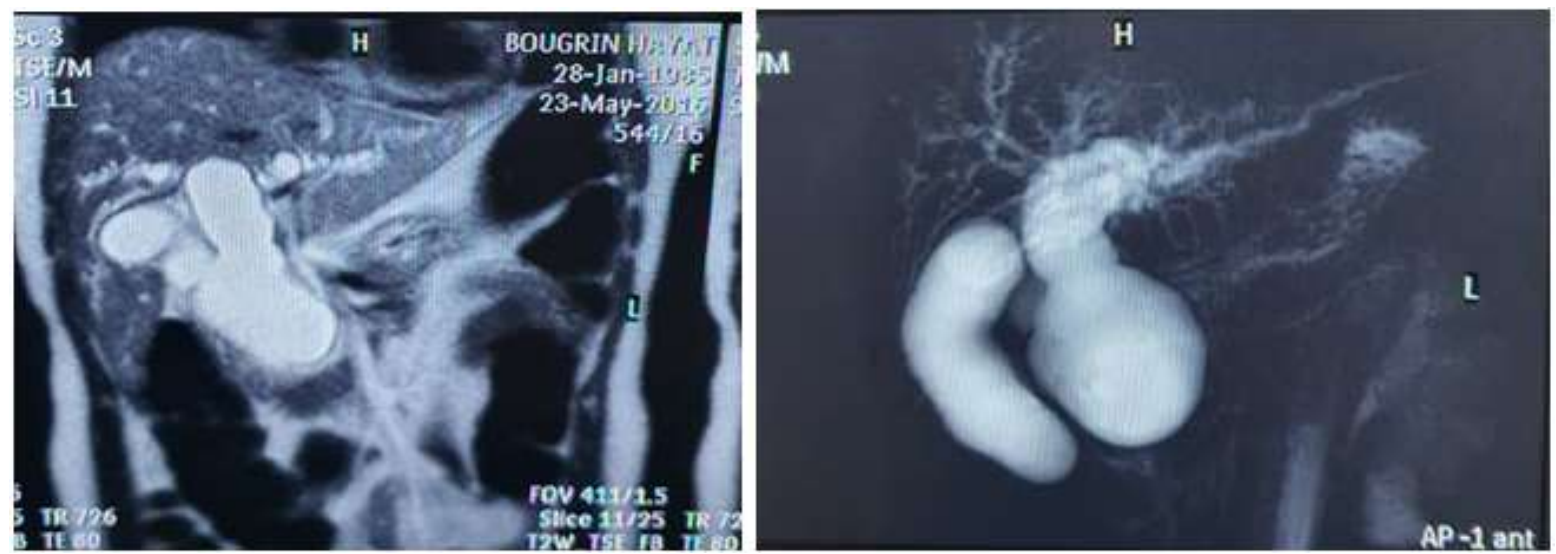

Fig-2: Total excision of the cyst with intramural dissection of the bile duct 


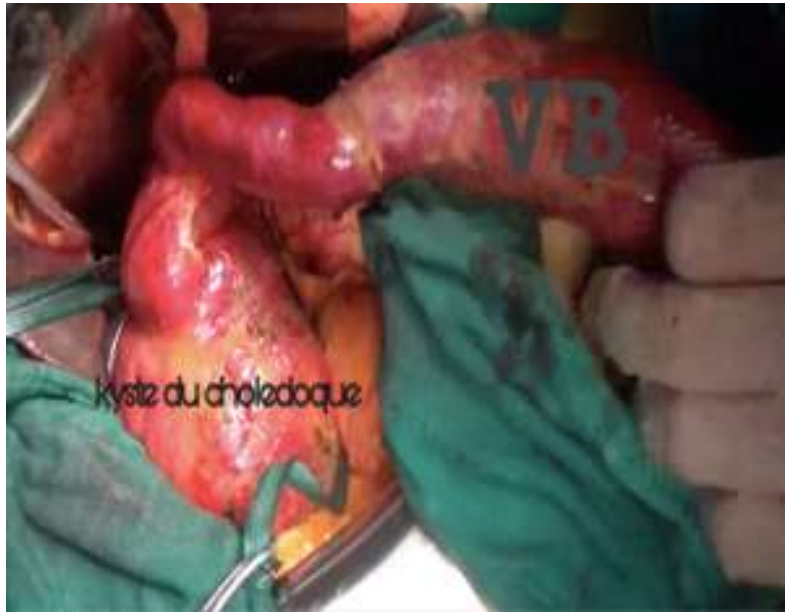

A: Cholédoque dissected and put on lake

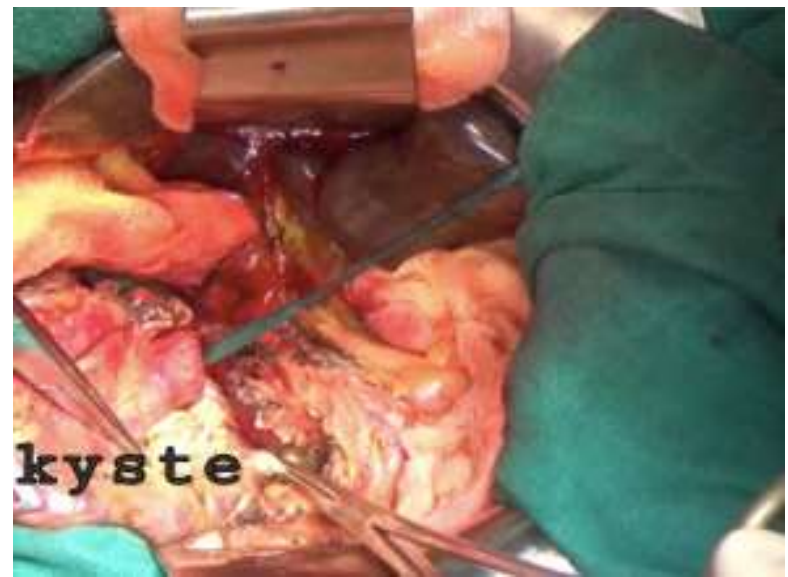

B: Section at the low bile duct after intracancreatic dissection

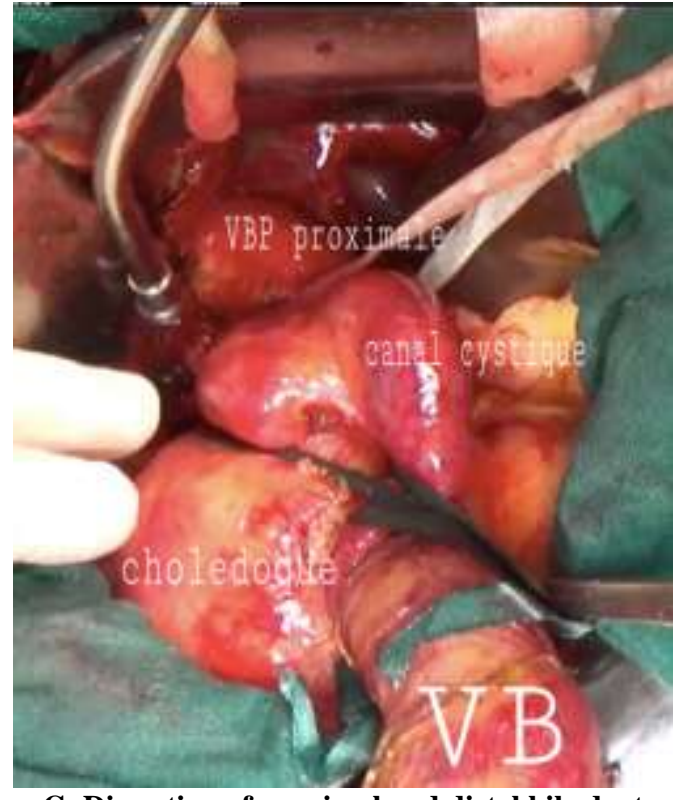

C: Dissection of proximal and distal bile duct

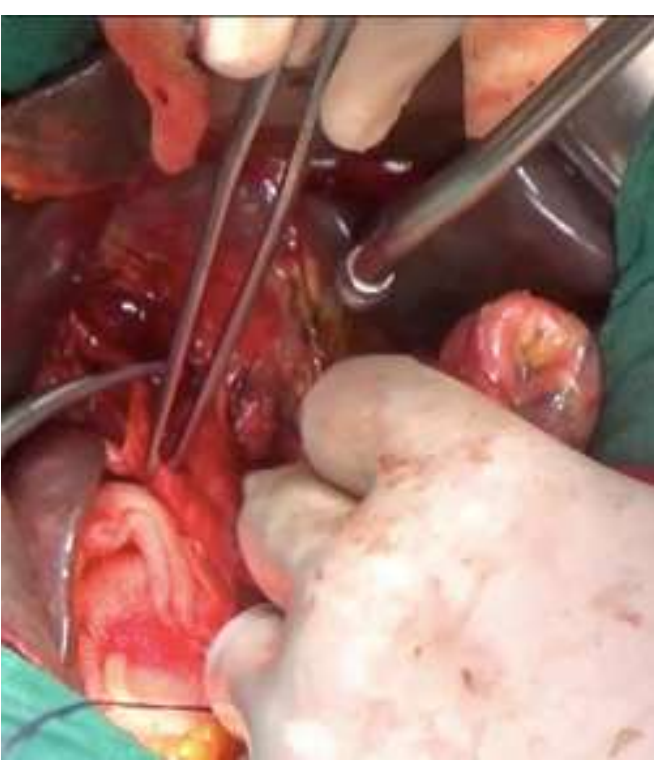

D: Section of the main bile duct at the level of the upper biliary convergence

Fig-3: Todani Classification

Type I ( $80 \%)$ : Dilatation of extrahepatic
biliary duct $\begin{aligned} & \text { Type II (10\%): Diverticulum of the } \\ & \text { Common Bile Duct }\end{aligned}$




\section{DISCUSSION}

Choledocal cyst is a rare malformation of the bile ducts, described by VATER in 1723 and later [1]. It is frequently found in infants and young children in the first decade of life [2] but can occur at any age. The incidence of $\mathrm{CC}$ ranges from 1 in 100,000 to 1 in 150,000 in Western countries [3] to 1 in 13,000 in Japan [4], with a clear female predominance reported by most authors of 70-80\% [5]. Many theories have been proposed to explain the origin of these malformations. The most commonly accepted theory is the one put forward by Babbit in 1969, which incriminated an anomaly of the biliopancreatic junction [6]. This malformation of fusion between the biliary and pancreatic ducts is characterized by three criteria a common duct more than $15 \mathrm{~mm}$ long; an extraduodenal junction of the two ducts at a distance from the sphincters; an angle of connection greater than $30^{\circ}$ [7]. The triad of right hypochondrium pain with hepatic colic, jaundice and a palpable right subcostal mass is very suggestive, but only occurs in 20 to $63 \%$ of cases. Most often, the picture is reduced to abdominal pain in adults and jaundice in children. DKC can be longlasting and may be discovered accidentally or as a result of complications [2,4,5]. The radiological step is essential for diagnosis. Hepato-biliary ultrasound shows an independent cystic mass of the gallbladder or the existence of an enormous dilatation of the bile ducts. This is more difficult in the presence of a cystic pocket full of stones. It also makes it possible to assess the state of the intrahepatic bile ducts [8]. The CT scan shows a very limited fluid tumour extended between the portal confluence and the duodenum, supplemented if necessary by a delayed cholangio-scan [9]. Direct opacifications of the bile ducts (endoscopic retrograde cholangio-graphy and transepatic cholangiography) allowing the jaundice to be linked to its cause were previously indispensable for preoperative diagnosis by clarifying the image of the biliopancreatic junction, currently less and less used with the advent of magnetic resonance imaging, a non-invasive examination that does not require contrast and allows reconstruction of the biliary tree, allows diagnosis and classification of lesions with high sensitivity (70\% to 100\%) and specification (90\% to 100\%) [10]. The Todani classification is the most widely used to characterize lesions (figure 6) [11].

Apart from surgical treatment, the evolution is unfavourable, marked by the occurrence of chronic cholestasis and infection followed by the development of secondary biliary cirrhosis. Acute complications such as recurrent angiocholitis, liver abscess, septicaemia, pancreatitis and more rarely DKC rupture or perforation leading to biliary peritonitis [12]. Cancerization is a rare complication but makes the prognosis bleak, the risk of DKC degeneration is $10 \%$ to $30 \%$ [13]. It occurs in young adults. In $80 \%$ of cases it is a cholangiocarcinoma. The incidence of this cancer increases with age [14] and after cysto-digestive shunts or after incomplete removal [15]. The treatment is surgical (figure 7), Total excision of the cyst with intramural dissection of the bile duct to its intra pancreatic portion followed by hepatic-jejunal anastomosis on a jejunal loop excluded in "Y" appears to be the procedure of choice [12], Laparoscopic resection gives results comparable to open resection in retrospective analyses $[16,17]$. The benefit of this type of surgery remains to be demonstrated because the prognosis is generally poor and survival rarely exceeds two years [18].

\section{CONCLUSION}

The risk of malignant transformation justifies surgery for cystic dilatations of the bile duct by early rese, whatever the age with intramural dissection of the common bile duct up to its intra pancreatic portion, accompanied by a hepatico-jejunal anastomosis on a $\mathrm{Y}$ mounted loop.

Conflicts of Interest: No conflicts of interest.

\section{REFERENCES}

1. Vater, A. (1723). Dissertatio de scirrhis viserum occasione sections viri typanite defunte. Wittenburgae, 4 Pamphlers, 881, 22.

2. Huang, C. S., \& Huang, C. C. (2010). Choledochal cysts: differences between pediatric and adult patients. Journal of Gastrointestinal Surgery, 14(7), 1105-1110.

3. Lee, H. K., Park, S. J., Yi, B. H., Lee, A. L., Moon, J. H., \& Chang, Y. W. (2009). Imaging features of adult choledochal cysts: a pictorial review. Korean journal of radiology, 10(1), 71-80.

4. Sato, M., Ishida, H., Konno, K., Naganuma, H., Ishida, J., Hirata, M., ... \& Watanabe, S. (2001). Choledochal cyst due to anomalous pancreatobiliary junction in the adult: sonographic findings. Abdominal imaging, 26(4), 395-400.

5. Soares, K. C., Arnaoutakis, D. J., Kamel, I., Rastegar, N., Anders, R., Maithel, S., \& Pawlik, T. M. (2014). Choledochal cysts: presentation, clinical differentiation, and management. Journal of the American College of Surgeons, 219(6), 1167-1180.

6. Babbit, D. P. (1969). Congenital choledochal cyst: new etiological concept based on anomalous relationships of the common bile duct and pancreatic bulb. Ann Radiol, 12, 231-240.

7. The Japanese study group on pancreatico biliary maljunction. Diagnostic criteria of pancreatico biliary maljunction. (1994). J Hepatobiliary Pancreatol Surg, 1:219-21.

8. Edil, B. H., Cameron, J. L., Reddy, S., Lum, Y., Lipsett, P. A., Nathan, H., ... \& Schulick, R. D. (2008). Choledochal cyst disease in children and adults: a 30-year single-institution experience. Journal of the American College of Surgeons, 206(5), 1000-1005.

9. Vullierme, M. P., Vilgrain, V., Zins, M., Sibert, A., Denis, A., \& Belghiti, J. (1997). Dilatations 
kystiques congénitales de la voie biliaire principale. Gastroenterol Clin Biol, 21, 201-208.

10. Sugiyama, M., Baba, M., Atomi, Y., Hanaoka, H., Mizutani, Y., \& Hachiya, J. (1998). Diagnosis of anomalous pancreaticobiliary junction: value of magnetic resonance cholangiopancreatography. Surgery, 123(4), 391397.

11. Kianmanesh, R., REGIMBEAU, J. M., \& Belghiti, J. (2001). Anomalies de la jonction biliopancréatique et dilatations kystiques congénitales des voies biliaires de l'adulte. Journal de chirurgie (Paris. 1908), 138(4), 196-204.

12. Zheng, L. X., Jia, H. B., Wu, D. Q., Shang, H., Zhong, X. Y., Wang, Q. S., ... \& Sun, Z. H. (2004). Experience of congenital choledochal cyst in adults: treatment, surgical procedures and clinical outcome in the Second Affiliated Hospital of Harbin Medical University. Journal of Korean Medical Science, 19(6), 842-847.

13. Jan, Y. Y., Chen, H. M., \& Chen, M. F. (2000). Malignancy in choledochal cysts. Hepatogastroenterology, 47(32), 337-340.

14. Fieber, S. S., \& Nance, F. C. (1997). Choledochal cyst and neoplasm: a comprehensive review of 106 cases and presentation of two original cases. The American surgeon, 63(11), 982.

15. Todani, T., Watanabe, Y., Toki, A. E., \& Urushihara, N. (1987). Carcinoma related to choledochal cysts with internal drainage operations. Surgery, obstetrics, 164(1), 61 .

16. Liuming, H., Hongwu, Z., Gang, L., Jun, J., Wenying, H., Wong, K. K. Y., ... \& Li, L. (2011). The effect of laparoscopic excision vs open excision in children with choledochal cyst: a midterm follow-up study. Journal of Pediatric Surgery, 46(4), 662-665.

17. Tian, Y., Wu, S. D., Zhu, A. D., \& Chen, D. X. (2010). Management of type I choledochal cyst in adult: totally laparoscopic resection and Roux-en-Y hepaticoenterostomy. Journal of Gastrointestinal Surgery, 14(9), 1381-1388.

18. Lee, S. E., Jang, J. Y., Lee, Y. J., Choi, D. W., Lee, W. J., Cho, B. H., \& Kim, S. W. (2011). Choledochal cyst and associated malignant tumors in adults: a multicenter survey in South Korea. Archives of Surgery, 146(10), 1178-1184. 